GRADIATION\&APPLICATIONS

ISSN 2466-4294 (online) | rad-journal.org

Vol. 3 | Issue 1 | pp. 7-12, 2018

doi: 10.21175/RadJ.2018.01.002

Original research paper

\title{
EFFECTS OF TRANSITION-METAL-DOPING ON THE RADIO-LUMINESCENCE PROPERTIES OF MAGNESIUM ALUMINATE SPINEL CRYSTALS*
}

\author{
Vasyl Gritsyna $^{1^{* *}}$, Yurij Kazarinovi,2 \\ ${ }^{1}$ V.N. Karazin Kharkiv National University, Kharkiv, Ukraine \\ ${ }^{2}$ National Scientific Center “Kharkiv Institute of Physics and Technology”, Kharkiv, Ukraine
}

\begin{abstract}
The use of the radio-luminescence ( $R L)$ method for radiation-induced processes in magnesium aluminates spinel crystals $\left(\mathrm{MgO} \cdot \mathrm{nAl}_{2} \mathrm{O}_{3}\right)$ of different composition doped with transition metals $(\mathrm{Mn}$, Cr, and $\mathrm{Fe})$ was investigated. The RL spectra demonstrate bands related to the intrinsic defects, such as anti-site defects (263 nm) and F-type centers ( $360 \mathrm{~nm})$. Transition metal (TM) ions substituting the crystal-forming ions in the tetra- and octahedral sites show the emission due to electron transitions in doped ions, particularly, band at 520 nm identified with the transition in $\mathrm{Mn}^{2+}$ in tetrahedral positions and the emission in the red spectral region (consisting of zerophonon line at $686.6 \mathrm{~nm}$ and phonon-assisted lines) related to the transition in $\mathrm{Cr}^{3+}$ ions at the octahedral position. Based on the data on the quenching UV luminescence in stoichiometric crystals doped with TM, we suggest the partial ordering of this type of crystals. The enhancement of $\mathrm{Cr}^{3+}$ luminescence in stoichiometric spinel crystals doped with manganese and iron supports this suggestion on the ordering of the spinel crystals by doping with some TM's. The existence of a large number of non-stoichiometric cationic vacancies in non-stoichiometric spinel crystals prevents the formation of an ordered structure.
\end{abstract}

Key words: Radio-luminescence, emission spectra, magnesium aluminate spinel, ordered crystals

\section{INTRODUCTION}

Magnesium aluminates spinel ( $\left.\mathrm{MAS}-\mathrm{MgAl}_{2} \mathrm{O}_{4}\right)$ is a high temperature insulator which demonstrates the high resistance to irradiation and is considered as a material for potential application in different devices [1]. At the present time, technologies have been developed to produce MAS either in forms of single crystals or in forms of large blocks of transparent ceramics suitable for opto-electronics, optical parts, transparent windows, and transparent armor [2].

The transition-metal (TM) doped MAS also attracts attention of many research groups due to different useful acquired characteristics of this material with transition metals. Particularly, chromium doped spinel crystals grown using the floating zone technique have been investigated as potentially useful sensor probes for the fiber-optic thermometer [3]. Vanadium doped MAS demonstrates a very broad (white) emission spectrum covering the visible region by three kinds of emission bands around 500, 600, and $700 \mathrm{~nm}$ that allow to use it as a white light source [4]. The X-ray stimulated luminescence (RL) intensity from manganese-doped spinel is very high [5].

The natural spinel crystals containing different concentrations of transition metals are highly ordered [6]. The MAS crystals, grown by different techniques, demonstrate the partial cationic inversion, i.e. some numbers of $\mathrm{Al}^{3+}$ are located in the tetrahedral position forming $\left[\mathrm{Al}_{\text {tet }}\right]^{+}$-defects with excess of the positive charge and the same number of $\mathrm{Mg}^{2+}$ takes the octahedral position leading to $\left(\mathrm{Mg}_{\text {oct }}\right)^{-}$-defects with excess of the negative charge. These anti-site defects serve as traps for released charge carriers under an Xirradiation forming hole and electron centers according to reactions $\left(\mathrm{Mg}_{\text {oct }}\right)^{-}-\mathrm{h}^{+} \rightarrow\left(\mathrm{Mg}_{\text {oct }}\right)^{\circ}$-center, and $\left[\mathrm{Al}_{\text {tet }}\right]^{+}+\mathrm{e}^{-} \rightarrow\left[\mathrm{Al}_{\text {tet }}\right]^{0}$-center. The energy of electron affinity in $\left[\mathrm{Al}_{\text {tet }}\right]^{\mathrm{o}}$-center is very low and, at room temperature, the decay of the unstable $\left[\mathrm{Al}_{\text {tet }}\right]^{\circ}$ centers leads to the release electrons which recombine with localized holes at $\left(\mathrm{Mgoct}^{\circ}{ }^{\circ}\right.$ centers causing the UVemission. This process was observed in thermostimulated luminescence of $\mathrm{X}$-irradiated crystals having the glow peak near room temperature [7], [8].

Therefore, if the doping with TM ions is present during the growth of spinel crystals, we may expect the influence of these ions on the degree of disordering and, consequently, on the physical properties of crystals. It was revealed that luminescent characteristics of $\mathrm{Mn}^{2+}$ and $\mathrm{Cr}^{3+}$ ions in spinels correlate with the disordering process during the heating of the natural spinel [9]. This paper is devoted for application of the RL for investigations the changes of properties of spinel single crystals of different compositions at the activation with $\mathrm{TM} \mathrm{Cr}, \mathrm{Mn}$, and $\mathrm{Fe}$.

\footnotetext{
* The paper was presented at the Fifth International Conference on Radiation and Applications in Various Fields of Research (RAD 2017), Budva, Montenegro, 2017.

vtgritsyna@karazin.ua
} 
V. Gritsyna, Yu. Kazarinov, Effects of transition-metal-doping..., Rad. Applic., 2018, 3, 1, 7-12

\section{EXPERIMENTAL DETAILS}

The single crystals of MAS of two different molar compositions - $\mathrm{MgO} \cdot 1.0 \mathrm{Al}_{2} \mathrm{O}_{3}$ and $\mathrm{MgO} \cdot 2.5 \mathrm{Al}_{2} \mathrm{O}_{3}-$ were grown using the Verneuil method. Detail in growth parameters, morphological and structure properties of grown spinel crystals are described in [10]. Nominally pure spinel crystals were used and doped with transition metals in the amount of 0.01 or $0.1 \mathrm{wt}$ \% in terms of transition metals. The content of transition metals in grown single crystals is much lower - from 0.2 to 0.5 of the amount of activating metals introduced in the spinel powder [11]. The concentration of transition metals in different crystals has been determined using the instrumental neutron activation analysis technique and it is discussed in the main part of this paper. The content of uncontrolled impurities ( $\mathrm{Fe}, \mathrm{Si}, \mathrm{Ti}, \mathrm{Mn}, \mathrm{Co}, \mathrm{Ni}, \mathrm{Ga}, \mathrm{V}, \mathrm{Cr}$ ) was not higher than $4 \cdot 10^{-3}$ wt. \%. All grown crystals, both nominally pure (n. p.) and doped with $\mathrm{Mn}, \mathrm{Cr}$, are transparent in the spectral range of 200-830 $\mathrm{nm}$.

The radio-luminescence (RL) spectra was measured at room temperature using the setup containing the Xray unit (URS-55M) of $\mathrm{Cu}$ anticathode operated at the voltage of $40 \mathrm{kV}$ and the current up to $10 \mathrm{~mA}$ and the optical recording system. The emitted light from the irradiated surface of samples was analyzed with a grating monochromator (MDR-1) and registered with a photomultiplier FEU-39. The RL was recorded using an ordinary plotter with subsequent digitations. In previous paper there was observed growth of luminescence intensity in dependence on the Xirradiation time [12]. In this research it was measured stationary luminescence after prolonged irradiation up to saturation in intensity of luminescence.

\section{EXPERIMENTAL RESULTS}

\subsection{Nominally Pure Spinel Crystals}

The RL spectra of the (n. p.) spinel crystals of the investigated composition - $\mathrm{MgO} 1.0 \mathrm{Al}_{2} \cdot \mathrm{O}_{3}$ and $\mathrm{MgO}$ $2.5 \mathrm{Al}_{2} \cdot \mathrm{O}_{3}$ - show four bands of different intensity (Fig.1).

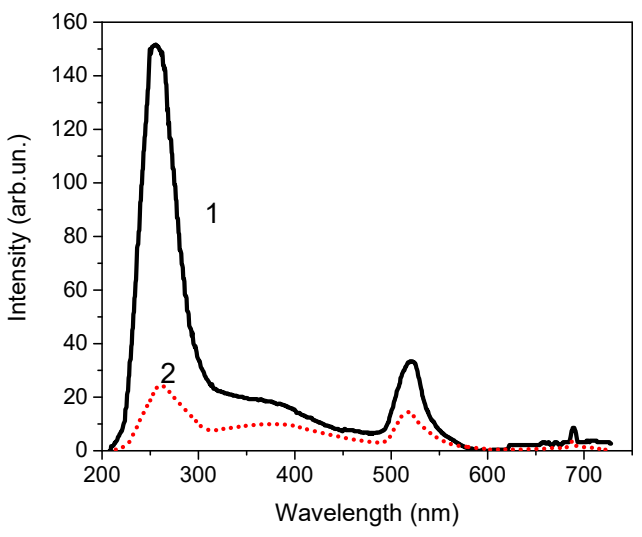

Figure 1. Radio-luminescence spectra of nominally pure magnesium aluminate spinel crystals of different compassions $\mathrm{MgO} \cdot \mathrm{nAl}_{2} \mathrm{O}_{3}: 1$ - $\mathrm{n}=1.0 ; 2-\mathrm{n}=\mathbf{2 . 5}$
The overall RL intensity of a stoichiometric crystal is much higher in comparison with a nonstoichiometric one. The spectroscopic characteristics of bands are also slightly different. For stoichiometric crystals in the UV range, the band at the wavelength of $253.0 \mathrm{~nm}$ was observed in our previous investigations and was identified to intrinsic defects of the spinel [8], [13]. This band most probably arises from the electronhole recombination process which includes anti-site defects. In non-stoichiometric crystals, this band is drastically decreased in intensity. In the blue range of RL, several bands are overlapping, giving the maximum of about $360 \mathrm{~nm}$ and, most probably, they are related to the emission from F-type centers, i.e. anionic vacancies that captured one or two electrons [14].

The origin of the band at the wavelength of $520 \mathrm{~nm}$ in stoichiometric crystals was also studied before and it is related to uncontrolled impurity ions $\mathrm{Mn}^{2+}$ in the tetrahedral position [15]. Despite the low concentration of manganese ions which was estimated in n. p. crystals at the level lower than $10^{-3}$ wt. \%, the intensity of this band is significant due to the high efficiency of conversion of the deposited radiation energy into the emission of light. The maximum of this band for the non-stoichiometric spinel is situated at $517 \mathrm{~nm}$ and the intensity is lower. Finally, in the red range of RL spectra, the emission of $\mathrm{Cr}^{3+}$ ions in the octahedral position was observed to have the features characteristic for this ion structure: zero-phonon line at $686.6 \mathrm{~nm}$ and good resolved phonon-assisted lines. In the non-stoichiometric spinel, the intensity of this emission is very low, the zero-phonon line is shifted to the wavelength of $688.0 \mathrm{~nm}$ and phonon assisted lines almost disappear.

\subsection{Manganese-Doped Spinel Crystals}

The RL spectra of stoichiometric crystals doped with manganese to the concentration of $0.01 \mathrm{wt}$. \% are depicted in Fig.2. The drastic decrease of the UV band intensity in stoichiometric crystals compared with $\mathrm{n}$. $\mathrm{p}$. crystals is explained taking into account the origin of electron-hole recombination luminescence in spinel based on the structure of crystals suggesting a decrease of anti-site defect concentration.

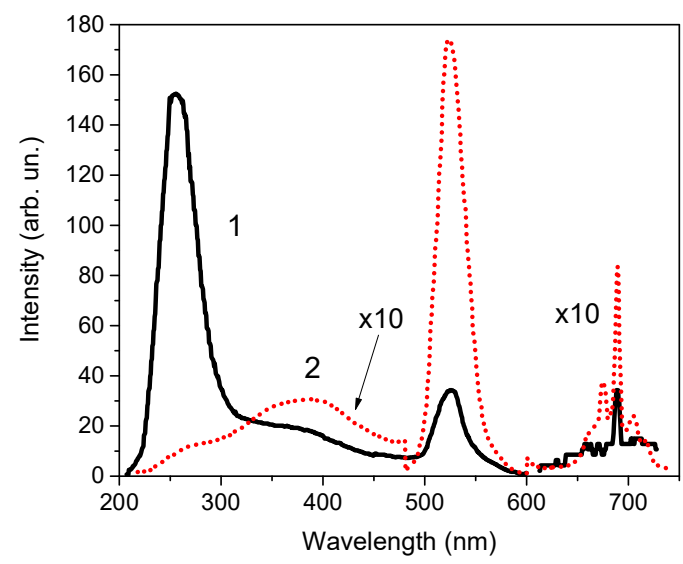

Figure 2. Radio-luminescence of n. p. (1) and stoichiometric spinel crystals doped with manganese $\mathrm{MgO} \cdot 1.0 \mathrm{Al}_{2} \mathrm{O}_{3}: \mathrm{Mn}$ (2) 
The intensity of the emission band at $520 \mathrm{~nm}$ also enhanced due to the growth of manganese ion concentration in the tetrahedral position. The asymmetric shape of this emission band reflects the fact that $\mathrm{Mn}^{2+}$ ions have preferential energy that equals zero and that they can take both tetra- and octahedral sites. Also, we observed the growth of the intensity of emission of $\mathrm{Cr}^{3+}$ ions by several times in comparison to n. p. crystals. In the manganese-doped nonstoichiometric spinel crystals, the green emission band shifts to $517 \mathrm{~nm}$ and the luminescence intensity increases more than ten times in comparison to $\mathrm{n}$. crystals p. (Fig. 3). The intensity of the UV emission does not practically change, but the intensity of luminescence, due to F-type centers, increases almost by factor two. The intensity of the emission from excited $\mathrm{Cr}^{3+}$ ions also slightly increases in comparison with n. p. crystals.

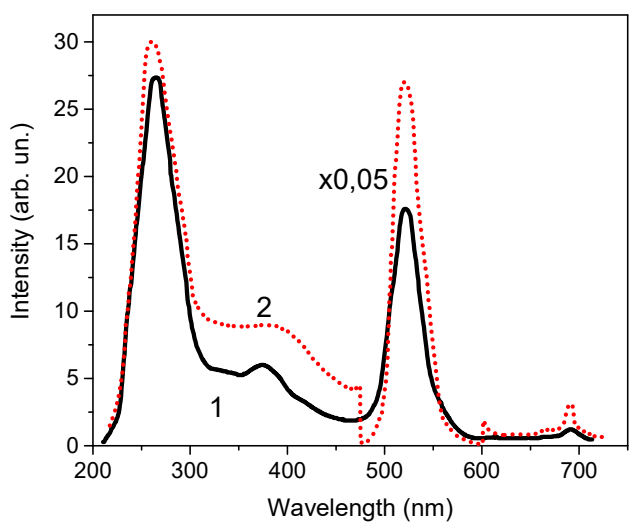

Figure 3. Radio-luminescence of n. p. (1) and nonstoichiometric spinel crystals doped with manganese $\mathrm{MgO} \cdot 2.5 \mathrm{Al}_{2} \mathrm{O}_{3}: \mathrm{Mn}(2)$

\subsection{Chromium-Doped Spinel Crystals}

The effect of doping of stoichiometric spinel crystals with chromium on the RL spectra is depicted in Fig. 4.

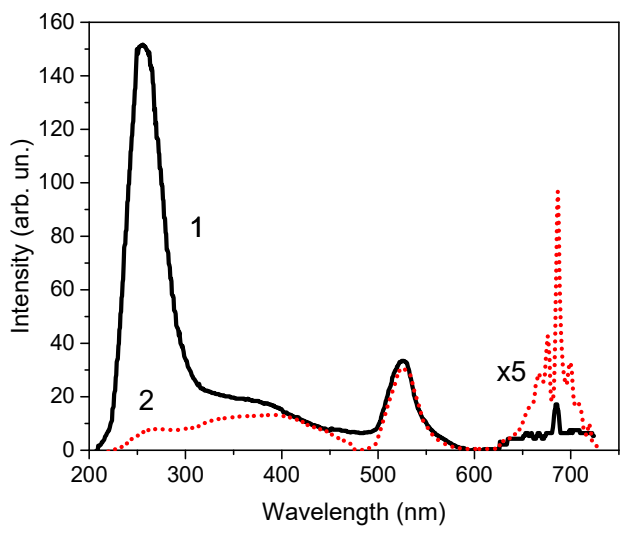

Figure 4. Radio-luminescence of n. p. (1) and stoichiometric spinel crystals doped with chromium $\mathrm{MgO} \cdot 1 \cdot \mathrm{OAl}_{2} \mathrm{O}_{3}: \mathrm{Cr}(2)$
Again, for stoichiometric spinel doped with chromium, the intensity of the UV band drastically decreases, whereas the emission of F-type centers and uncontrolled impurity $\mathrm{Mn}^{2+}$ ions remain practically unchanged. The intensity of the emission of $\mathrm{Cr}^{3+}$ ions (having zero-phonon line at $686.6 \mathrm{~nm}$ and phonon assisted satellites) increases several times in comparison to n. p. crystals. The changes of the luminescence spectra from non-stoichiometric to the ones doped with different concentrations of chromium are shown in Fig. 5. When the non-stoichiometric crystals are doped with chromium, the intensity of all emission bands gradually drops except for the luminescence of $\mathrm{Cr}^{3}$ which increases two and four times when the concentration of added chromium is 0.01 and 0.1 wt. \%, respectively.

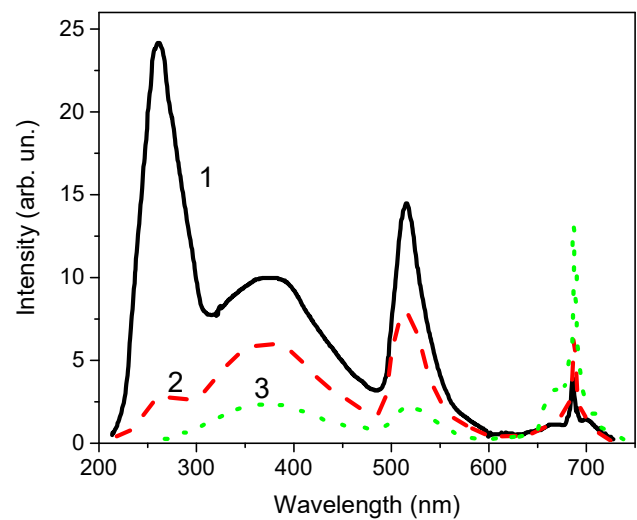

Figure 5. Radio-luminescence of n. p. (1) and nonstoichiometric spinel crystals doped with chromium $\mathrm{MgO} \cdot 2.5 \mathrm{Al}_{2} \mathrm{O}_{3}: \mathrm{Cr}$ of different concentration: 0.01 wt. \% (2) and 0.1 wt. \% (3)

$\mathrm{Cr}^{3+}$ ions have a large preferential energy to octahedral sites, the size of which practically does not depend on the composition of spinel crystals [16]. Therefore, the doping of spinel crystals with chromium causes the smallest effect on the structural properties of both stoichiometric and non-stoichiometric crystals.

\subsection{Iron-Doped Spinel Crystals}

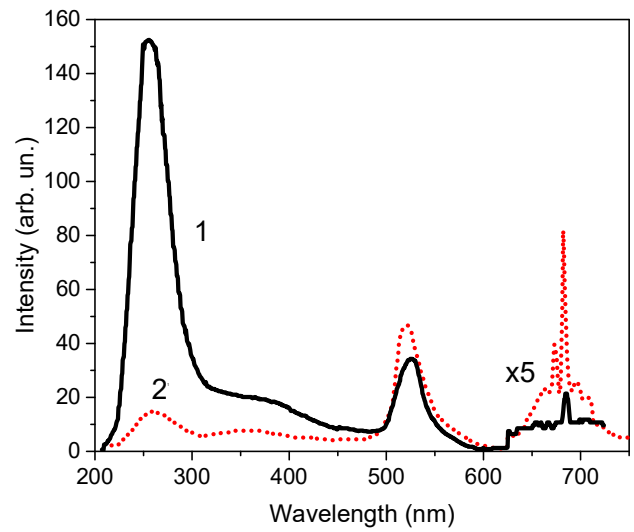

Figure 6. Radio-luminescence of n. p. (1) and stoichiometric spinel crystals doped with iron $\mathrm{MgO} \cdot 1.0 \mathrm{Al}_{2} \mathrm{O}_{3}: \mathrm{Fe}$ (2) 
Iron ions are unavoidable impurities in spinel crystals as artificially grown and natural gems. In our n. p. crystals, the concentration of iron was at the level of $2 \cdot 10^{-3}$ wt. \%. Therefore, if the doping with iron reaches the concentration of $0.01 w \%$, the intensity of the UV-band decreases almost ten times, indicating the strong dependence of this band on the presence of iron (Fig. 6).

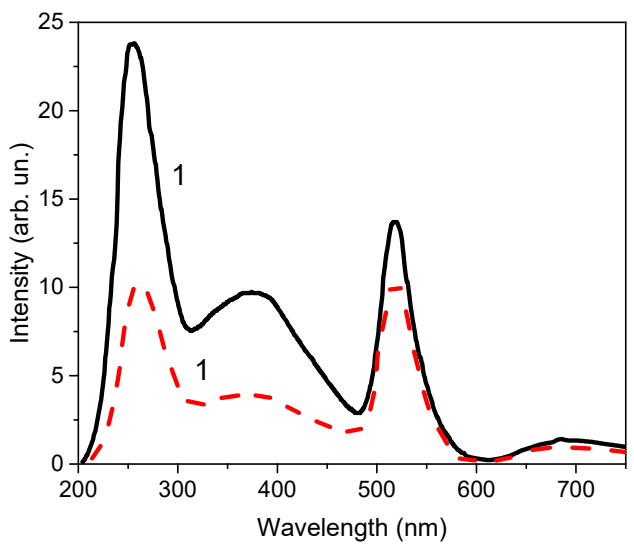

Figure 7. Radio-luminescence of n. p. (1) and nonstoichiometric spinel crystals doped with iron $\mathrm{MgO} \cdot 2.5 \mathrm{Al}_{2} \mathrm{O}_{3}: \mathrm{Fe}(2)$

\section{DISCUSSION}

The relative intensities of all luminescence bands in investigated spinel crystals are presented in Table 1. The difference of the RL spectra in the n. p. spinel crystals of different compositions is defined by structural peculiarities. The MAS is a complex oxide compound $\mathrm{MgO} \cdot \mathrm{nAl}_{2} \mathrm{O}_{4}$ that forms a single phase spinel structure at the variation of composition in the range of $1.0<\mathrm{n}<3.5$. Also, at the excess of aluminum oxide $(n>1.0)$, the spinel structure becomes defective because the extra $\mathrm{Al}^{3+}$ ions occupy the tetrahedral position and, for charge compensation, the additional cationic vacancies in octahedral sites are formed.

Table 1. Relative intensities of the RL bands in spinel crystals of different compositions and doped with transition metals

\begin{tabular}{|c|c|c|c|c|c|}
\hline \multirow[b]{2}{*}{ Crystal } & \multirow{2}{*}{$\begin{array}{l}\text { Doped, } \\
\text { mass\% }\end{array}$} & \multicolumn{4}{|c|}{ Luminescent species } \\
\hline & & $\begin{array}{l}\text { UV- } \\
\text { band }\end{array}$ & $\begin{array}{c}\mathrm{F}- \\
\text { type }\end{array}$ & $\mathrm{Mn}^{2+}$ & $\mathrm{Cr}^{3+}$ \\
\hline \multirow{4}{*}{$\begin{array}{l}\mathrm{MgO} \cdot \\
\text { 1. } \mathrm{OAl}_{2} \mathrm{O}_{3}\end{array}$} & n.p. & 153 & 20 & 33 & 3.2 \\
\hline & Mn-0.01 & 0.6 & 3.5 & 174 & 8.4 \\
\hline & Cr-0.01 & 1.5 & 3 & 32 & 19.5 \\
\hline & Fe-0.01 & 14 & 8 & 47 & 16 \\
\hline \multirow{5}{*}{$\begin{array}{l}\mathrm{MgO} \cdot \\
2.5 \mathrm{Al}_{2} \mathrm{O}_{3}\end{array}$} & n.p. & 27 & 6 & 18 & 1.5 \\
\hline & Mn-0.01 & 15 & 4,4 & 550 & 1.6 \\
\hline & Cr-0.01 & 2.6 & 6.0 & 8.0 & 6.2 \\
\hline & Cr-0.1\% & - & 2.1 & 2.1 & 12.7 \\
\hline & Fe-0.01 & 10 & 3.85 & 10 & - \\
\hline
\end{tabular}

Therefore, the spinel structure of nonstoichiometric crystals contains a large amount of the charge compensated cationic vacancies that makes spinel lattice more disordered. Also, due to the lower 10 size of $\mathrm{Al}^{3+}$ ions (o.19 nm) in oxide compounds in comparison to $\mathrm{Mg}^{2+}(0.21 \mathrm{~nm})$, the crystal lattice parameter decreases. In our case, stoichiometric crystals $(\mathrm{n}=1.0)$ have $\mathrm{a}=0.80835 \mathrm{~nm}$, the nonstoichiometric ones $-\mathrm{a}=0.79855 \mathrm{~nm}$. The additional cationic vacancies of non-stoichiometric origin influence the spatial distribution of anti-site defects and, consequently, the inter-center spacing of the $\left(\mathrm{Al}_{\text {tet }}\right)^{\mathrm{O}}$ and $\left(\mathrm{Mg}_{\mathrm{oct}}\right)^{\circ}$ centers that cause the drastic decrease of the intensity of electron-hole recombination luminescence (UV-band). The second effect that influences the intensity of the UV band is the decrease of the number of $\mathrm{Mg}^{2+}$ ions in the octahedral position. As one can see in Table 1, the intensity of the UV band in n. p. non-stoichiometric crystals decreases by factor 6 in comparison with the stoichiometric ones.

At the growth process of doped crystals, the transition metal ions are distributed at tetra- and octapositions in spinel lattice according to the valence state, ionic radius and preferential energy to octahedral sites. For all doped stoichiometric crystals irrespective of TM ions, the sharp decrease of the intensity of UV band was observed that could be because of the decrease of the number of electron-hole centers $\left(\mathrm{Al}_{\text {tet }}\right)^{\circ}$ and $\left(\mathrm{Mg}_{\text {oct }}\right)^{\circ}$ that lead to electron-hole recombination luminescence. The decrease of luminescence centers at anti-site defects in stoichiometric spinel may be the effect of doping with TM ions on the ordering of cations $\mathrm{Mg}^{2+}$ and $\mathrm{Al}^{+}$among tetra- and octahedral sites forming a normal spinel structure.

The effect of the reduction of the intensity of the UV-band when non-stoichiometric crystals are doped with TM is much weaker. Even more, the manganese doped non-stoichiometric crystal shows almost the same intensity of UV band as from the nominally pure crystals. The existence of a large concentration of nonstoichiometric vacancies prevents the crystal field effects of TM ions from spreading on large distances to meke ordering of these crystals. The strength of the crystal field for TM ions in both tetra- and octahedral position will be larger and the crystal lattice will be more distorted in the non-stoichiometric crystal in comparison to the stoichiometric one.

In emission spectra of stoichiometric spinel crystals doped with manganese ions, the band at $520 \mathrm{~nm}$ was identified with the transition from excited ${ }^{4} \mathrm{~T}_{1}\left({ }^{4} \mathrm{G}\right)$ to the ground state ${ }^{6} \mathrm{~A}_{1}\left({ }^{6} \mathrm{~S}\right)$ of $\mathrm{Mn}^{2+}$ ions embedded in the tetragonal field. When the electron-hole pair is created during the X-ray irradiation, the $\mathrm{Mn}^{2+}$ ion in tetrahedral site attracts a hole at first, so that $\mathrm{Mn}^{3+}$ state is formed as an intermediate state and an electron from conduction band is radiatively annihilated leading to $\mathrm{Mn}^{2+}$ in an excited state [17].

The emission band of $\mathrm{Mn}^{2+}$ ions in nonstoichiometric spinels is shifter to shorter wavelength at the maximum of $518 \mathrm{~nm}$ due to the lower strength of the crystal field surrounding $\mathrm{Mn}^{2+}$ ions [18]. The existence of the large concentration of the nonstoichiometric vacancies in $\mathrm{MgO} \cdot 2.5 \mathrm{Al}_{2} \mathrm{O}_{3}$ crystals causes the formation of impurity-defect complexes of the local crystal field and symmetry.

The emission spectra of chromium doped stoichiometric spinel crystals demonstrates the decrease intensities of all bands except the emission in 
V. Gritsyna, Yu. Kazarinov, Effects of transition-metal-doping..., Rad. Applic., 2018, 3, 1, 7-12

the red region which is assigned to the transition in $\mathrm{Cr}^{3+}$ ions at octahedral sites. This emission consists of the zero-phonon line at the wavelength of $686.6 \mathrm{~nm}$ and well-developed phonon-assisted lines which arise from ${ }^{2} \mathrm{E}_{\mathrm{g}} \rightarrow{ }^{4} \mathrm{~A}_{2 \mathrm{~g}}$ transition in $\mathrm{Cr}^{3+}$ ion. The intensity of this emission is enhanced 6 times in comparison to nominally pure crystals.

The doping of non-stoichiometric spinel crystals with chromium also causes the increase of intensity of the red emission but only two times. The structure of spectra is poorly resolved as in undoped and chromium doped crystals. As it can be seen from Fig. 5, if the doping with chromium is ten times higher, then the intensity of emission increases 3 times in respect to the previous one.

In RL spectra of manganese doped stoichiometric crystals, there was the observed emission in the red part of spectra, which matched in the form and wavelength peaks to the emission of $\mathrm{Cr}^{3+}$ ions in the octahedral position, but it was 3 times more intense in comparison to nominally pure crystals. We exclude the possibility to introduce additional chromium ions when doped with manganese due to the good purity and low concentration of introduced $\mathrm{MnCO}_{3}$ $(c(M n)=0.01 w \%)$. The further increasing of the concentration of $\mathrm{MnCO}_{3}$ to $(\mathrm{Mn})=0.1$ wt. \% does not increase this emission at all. A comparison of the red luminescence intensity in the spectra of all TM-doped stoichiometric spine crystals and data in Table 1 shows the enhancement of $\mathrm{Cr}^{3+}$ emission that supports the effect of ordering of these crystals.

This data indicates that, even at the lowest concentration of manganese, practically all chromium ions (uncontrolled impurity) participate in emission processes. This effect supports the suggestion on the ordering of spinel crystals when doped with manganese and forming a proper crystal field in octahedral sites that lead to the enhancement of the optical strength of transitions in $\mathrm{Cr}^{3+}$ ions. Also, it is consistent with the results on the emission spectra of chromium-doped spinel crystals irradiated with fast neutrons [11]: at the fluence of $10^{20}$ netron $/ \mathrm{cm}^{2}$, the disordering is so high that spectra structure can not be clearly seen and the integral intensity of $\mathrm{Cr}^{3+}$ ion luminescence decreases.

According to a recent review devoted to luminescence of the transition metal complexes [19], iron oxide complexes are characterized as nonluminescent. Nevertheless, some individual kinds of iron-containing substances demonstrate the existence of the phenomenon of luminescence, particularly, in yttrium aluminum garnets where the emission with the wavelength at $800 \mathrm{~nm}$ due to transition in $\mathrm{Fe}^{3+}$ in tetrahedral position was observed [20]. We can conclude from Fig. 7 that the increase of iron concentration by two orders of magnitude leads to a very small change of luminescence intensity at $710 \mathrm{~nm}$. The reason is that iron doping leads simultaneously to the quenching of luminescence that we see for all bands, including the emission from $\mathrm{Fe}^{3+}$ ions. However, the sharp decrease of the UV luminescence band and increase of intensity of $\mathrm{Cr}^{3+}$ emission support the suggestion on the ordering effect of stoichiometric spinel crystals at the doping with this type of TM ions.

\section{CONCLUSION}

The investigation of radio-luminescence of the stoichiometric spinel crystals doped with transition metals show the sharp decrease of intensity of the UVband related to the electron-hole recombination of centers at anti-site defects. Also, doping with manganese iron leads to the enhancement of $\mathrm{Cr}^{3+}$ ion emission of the good resolved phonon components, indicating the proper crystal field in octahedral sites that surround this ion, which arises in a more ordered spinel structure.

Acknowledgement: This work was supported by Ministry of Education and Science of Ukraine (Grant o7-13-15). Authors are grateful to Prof. L. A. Lytvynov of the Institute for Single Crystals, NAS of Ukraine, who provided samples of spinel crystals.

\section{REFERENCES}

1. R. P. Gupta, "Radiation-Induced Cation Disorder in the Spinel MgAl2O4," J. Nucl. Mater., vol. 358, no. 1, pp. 35 - 39, Nov. 2006.

DOI: 10.1016/j.jnucmat.2006.05.3055

2. A. Krell, K. Waetzig, J. Klimke, "Influence of the Structure of $\mathrm{MgO} \cdot \mathrm{nAl}_{2} \mathrm{O}_{3}$ Spinel Lattices on Transparent Ceramics Processing and Properties," J. Eur. Ceram. Soc., vol. 32, no. 11, pp. $2887-2898$, Aug. 2012.

DOI: 10.1016/j.jeurceramsoc.2012.02.054

3. H. Aizava et al., "Characteristics of Chromium Doped Spinel Crystals for a Fiber-Optic Thermometer Application," Rev. Sci. Instrum., vol. 73, no. 8, pp. 3089 - 3092, Aug. 2002. DOI: $10.1063 / 1.1491998$

4. Y. Fujimoto et al., "Vanadium-Doped $\mathrm{MgAl}_{2} \mathrm{O}_{4}$ Crystals as White Light Source," J. Lumin., vol. 128, no. 3, pp. 282 - 286, Mar. 2008. DOI: 10.1016/j.jlumion.2007.07.022

5. T. Katsumata et al., "X-ray Excited Optical Luminescence from Mn Doped Spinel Crystals," ECS Solid State Let., vol. 3, no. 7, pp. R23 - R25, May 2014. DOI: 10.1149/2.0011407ssl

6. R. Martignago, A. Dal Negro, S. Carbonin, "How $\mathrm{Cr}^{3+}$ and $\mathrm{Fe}^{3+}$ Affect $\mathrm{Mg}$-Al Order-Disorder Transformation at High Temperature in Natural Spinels," Phys. Chem. Minerals, vol. 30, no. 7, pp. $401-408$, Aug. 2003. DOI: 10.1007/s00269-003-0336-0

7. A. Lorincz, M. Puma, F. J. James, J. H. Crawford, Jr., "Thermally Stimulated Processes Involving Defects in $\gamma$ - and X-irradiated spinel (MgAl2O4)," J. Appl. Phys., vol. 53, no. 2, pp. $927-932,1982$.

DOI: $10.1063 / 1.330562$

8. V. T. Gritsyna, Yu. G. Kazarinov, V. A. Kobyakov, I. E, Reimanis, "Radiation-induced luminescence in magnesium aluminate spinel crystals and ceramics," Nucl. Instr. Meth. B, vol. 250, no. 1-2, pp. $342-348$, Sep. 2006.

DOI: 10.1016/j.nimb.2006.04.135

9. J. M. G. Tijero, A. Ibarra, "Use of Luminescence of $\mathrm{Mn} 2+$ and $\mathrm{Cr}_{3}+$ in Probing the Disordering Process in MgAl2O4 Spinels," J. Phys. Chem. Solids, vol. 54, no. 2, pp. $203-207$, Feb. 1993. DOI: 10.1016/0022-3697(93)90309-F

10. G. I. Belykh, V.T. Gritsyna, L. A. Lytvynov, V. B. Kol'ner, "Structural and mechanical characteristics of magnesium-aluminate spinel crystals grown by Verneuil and Czochralski methods," Funct. Mater., vol. 12, no. 3, pp. $447-453,2005$. 
V. Gritsyna, Yu. Kazarinov, Effects of transition-metal-doping..., Rad. Applic., 2018, 3, 1, 7-12

Retrieved from: http://www.functmaterials.org.ua/cont ents/12-3/fm123-06.pdf;

Retrieved on: Jan 25, 2018

11. V. Skvortsova, N. Mironova-Ulmane, U. Ulmanis, "Neutron irradiation influence on magnesium aluminum spinel inversion," Nucl. Instr. Meth. B, vol. 191, no. 1-4, pp. 256 - 260, May 2002. DOI: 10.1016/So168-583X(02)00571-2

12. V. T. Gritsyna, I. V. Afanasyev-Charkin, V. A. Kobyakov, K.E. Sickafus, "Structure and Electronic States of Defects in Spinel of Different Compositions MgO·nAl2O3:Me," J. Am. Ceram. Soc., vol. 82, no. 12, pp. $3365-3373$, Dec. 1999 . DOI: 10.1111/j.1151-2916.1999.tbo2252.x

13. V. Gritsyna, Yu. Kazarinov, A. Moskvitin, "RadioLuminescence of Defects and Impurity Ions in Magnesium Aluminates Spinel," Sol. St. Phen., vol. 200, pp. $203-208$, Apr. 2013. DOI: 10.4028/www.scientific.net/SSP.200.203

14. S. S. Raj et al., "MgAl2O4 Spinel: Synthesis, Carbon Incorporation and Defect-Induced luminescence," J. Mol. Struct., vol. 1089, pp. 81 - 85, 2015. DOI: 10.1016/j.molstruc.2015.02.002

15. N. Mironova, V. Skvortsova, A. Smirnovs, L. Cugunov, "Distribution of Manganese Ions in Magnesium-
Aluminum Spinels of Different Compositions," Optical Mater., vol. 6, no. 3, pp. 225 - 232, Sep. 1996.

DOI: 10.1016/0925-3467(96)0o037-7

16. S. Lucchesi, A. Della Giusta, "Crystal chemistry of nonstoichiometric Mg -AI synthetic spinels," Z. Kristallogr. Cryst. Mater., vol. 209, no. 9, pp. 714 719, Sep. 1994.

DOI: 10.1524/zkri.1994.209.9.714

17. A. Tomita et al., "Luminescence Channels of Manganese-Doped Spinel," J. Luminesc., vol. 109, no. 1, pp. 19 - 24, Jul. 2004. DOI: 10.1016/j.jlumin.2003.12.049

18. T. Sakuma et al., "Compositional variation of photoluminescence from $\mathrm{Mn}$ doped $\mathrm{MgAl}_{2} \mathrm{O}_{4}$ Spinel," Opt. mater., vol. 27, pp. 302 - 305, Nov. 2014. DOI: 10.1016/j.optmat.2014.06.014

19. J. Sima, "(Non)luminescent Properties of Iron Compounds," Acta Chimica Slovaca, vol. 8, no. 2, pp. 126 - 132, Oct. 2015. DOI:10.1515/ACS-2015-0022

20. C. R. Varney et al., "Strong visible and Near Infrared Luminescence in Undoped YAG Single Crystals," AIP Adv., vol. 1, no. 4, 042170, 2011.

DOI: $10.1063 / 1.3671646$ 